\title{
An examination of improvements in co-disposal of waste rock with backfill
}

Chris Lee Golder Associates Ltd, Canada

Fangqiu Gu Golder Associates Ltd, Canada

\begin{abstract}
Most underground mines produce a significant quantity of development waste rock in order to access the orebody and provide underground excavations for mining infrastructure. Much of this development waste rock is hauled to surface in many mines and results in a substantial operating cost. In addition, most mines use cemented backfill to fill the stope voids that are not filled with waste rock and this cemented backfill represents a substantial operating cost as well.

Some mines do dispose of some development waste rock in stopes however the operational difficulties associated with disposing of a large quantity of rock in the stopes prevents many mines from taking advantage of this option.

One of the principal difficulties is the placement of backfill and waste rock in the right proportions so that there are no areas of waste rock only (i.e. rock that has no binding matrix to hold the rock particles together). Traditional methods of waste rock disposal in backfill stopes using scoops that dump their buckets over the brow have been severely limited by this constraint and resulted in limitations on the rate of waste rock delivery into the stope as well as the maximum amount of rock that can be placed into the stope. Delivery of waste rock from the development face to the stope can also be challenging if the distance is substantial. Scheduling of the development waste rock disposal in the available stopes can be difficult since the options for waste rock storage are typically limited on an active mining level and the peaks in development rock production may exceed the capacity of a stope to receive development waste rock.

This paper discusses procedures, methods and equipment that can be used to allow waste rock to be delivered more effectively to the stopes to lower a mines operating costs.
\end{abstract}

\section{Introduction}

The disposal of development was rock into stopes has a large impact on mining costs due to a reduction in waste hauled to surface and a reduction in the costs of backfilling. To assess the opportunity for improvement in mine economics by disposing of waste rock with the backfill the cost of the backfill and the cost of the waste rock haulage must be known. A simplified calculation of the impact of disposing of waste rock underground is shown below:

Table 1 Mining cost savings per tonne of waste rock produced (Theoretical example)

\begin{tabular}{crc}
\hline Cost of waste rock hoisting & $\$ 2.00$ & per tonne \\
Cost of haulage to dump & $\$ 2.50$ & per tonne \\
Cost of waste dump placement & $\$ 1.50$ & per tonne \\
Total waste rock disposal & $\$ 6.00$ & per tonne \\
\hline
\end{tabular}




\begin{tabular}{ccc}
\hline Cost of backfill & $\$ 10.00$ & per tonne \\
\hline Total differential & $\$ 16.00$ & per tonne \\
\hline
\end{tabular}

As described in the table above, the potential savings in mining costs per tonne of waste rock is $\$ 16.00$ per tonne of waste rock (assuming that waste rock and backfill dry densities are similar).

Since mining costs are calculated in $\$$ /tonne of ore, the impact of this savings on the mining costs also depends on the waste rock to ore ratio and for a 1:4 waste/ore ratio the total savings per tonne of ore would be $\$ 4.00$ per tonne in this example. For a 1 million tonne per annum mining rate this reduction in mining costs is equivalent to a $\$ 4$ million savings in yearly operating costs.

There are other factors that contribute to the cost savings such as tailings disposal costs, differential costs for hauling waste underground to the material handling circuit versus disposal in the stopes, traffic and ventilation considerations etc. All these costs should be added into the equation to determine the net reduction in operating costs.

In addition to the potential savings in operating costs, the removal of waste rock haulage from the materials handling system may allow some mines to mine more ore. This is especially true of shaft mines where there is no potential for adding more trucks or improving traffic management in order to increase haulage tonnages. The potential increase in revenue due to mining more ore with the same fixed costs is substantial.

\section{Previous attempts at waste rock co-disposal}

Many mines around the world have, to some degree implemented waste rock co-disposal into their mining method. Sometimes it is as simple as disposing of waste rock in secondary stopes where there is no requirement for fill strength. In other cases, effort has been made to co-dispose of waste rock in conjunction with cemented backfill with varying levels of effort and success.

Kuganathan (2001) describes the co-disposal of a cemented hydraulic fill slurry with graded rockfill at Mt. Isa mine. The combination of these two constituents yielded a homogenous fill that was not prone to segregation in the way the cemented rockfill was prone. The major disadvantage of that system was the cost of the capital equipment (conveyors etc.) to distribute the waste rock to the stopes.

Mt. Isa also experimented with the 'Christmas Tree' co-disposal method where uncemented rock was placed through a borehole into the center of a stope and cemented flowable fill (either paste or hydraulic fill) was placed around the cones of deposited rock. The uncemented waste rock was encapsulated in the cemented fill and served to fill the void while avoiding an uncemented wall at the edges of the stope that would be exposed upon extraction of the adjacent stope. This method allowed disposal of waste rock however it is not as beneficial for other mines with smaller stopes where the cost of fill passes to the center of the stope and the limited amount of rock that can be discharged into the stope (while maintaining a suitable barrier layer of cemented fill) makes the option less attractive.

Many mines also discharge scoop buckets over the brow of longhole stopes at a rate that is usually set to ensure that the uncemented rock is falling into a bed of uncured fill and is able to embed itself in the fill to some extent. This option is limited in terms of the amount of rock that can be safely discharged into the stope without creating pockets of uncemented fill that could result in dilution into the adjacent stope.

Almost all mines discharge waste rock into captive secondary stopes where no free faces will be exposed. This represents a good opportunity for waste rock disposal without issues around backfill dilution. However, the disposal of waste rock into secondary stopes only displaces low strength fill typically whereas waste rock disposal into primary stopes displaces more expensive fill.

In summary, waste rock disposal in underground stopes is a widespread practice however no operation has 
found the perfect solution to maximize the potential of the waste rock.

\section{The ideal characteristics of waste rock co-disposal}

To determine the best solution for waste rock co-disposal it is really necessary to set the criteria for what constitutes an ideal co-disposal system. Once those ideal criteria are set the next step is to determine if any equipment or procedures can be applied to meet those criteria.

The ideal waste rock disposal criteria are:

- Dispose of waste rock in high strength, primary stopes where the cost of backfill is the highest.

- Maintain or increase the strength of the overall cemented fill mass by incorporating waste rock.

- Eliminate material handling costs to transport waste rock to surface.

- Minimize operational effort to incorporate waste rock into the cemented fill (i.e. no significant amounts of extra equipment, no crushing, rehandling etc.).

- Allow the co-disposal of waste rock at all times (i.e. dispose of waste rock as it is produced so that no storage or rehandling is required).

\subsection{Disposal of waste rock in primary stopes}

As discussed previously in the review of current practices for waste rock co-disposal there are many mines that dispose of some waste rock in primary stopes but all of those efforts (to the authors knowledge) are incomplete solutions to the problem and result in only a small fraction of the waste rock being disposed of in the stope.

To allow disposal of waste rock throughout the stope it is considered likely that the waste rock and a cemented fill product must be mixed and then distributed around the stope so that larger particles are not prone to segregation.

This is practically difficult since methods of moving rock (truck, conveyors, raises) are different than moving paste-fill or hydraulic fill (pipelines). In addition, neither rock or paste transportation systems are amenable to distributing the material evenly around the stope since they generally discharge from a single location.

\subsection{Maintaining or increasing the fill strength}

Since the objective of backfill is to fill the stopes with the lowest cost material that can meet the required strength as possible it is desirable to have a broad distribution of particle sizes with the finer particles binding the larger particles together.

The concrete industry has optimized the gradation requirements for small particle cemented mixtures (usually less than $75 \mathrm{~mm}$ top size particle). This is primarily due to the limitations on larger particle size since larger particles can have localized detrimental impact for smaller pours and concrete is relied upon to be homogenous and uniform. However, for larger fill masses such as in backfilled stopes the use of larger particles is more attractive because the impact of larger particles on localized fill areas is not important given the lower standards required for backfill failure and dilution versus concrete where no concrete is expected to fail. For concrete the Talbot curve illustrates the ideal gradation required to maximize strengths. 


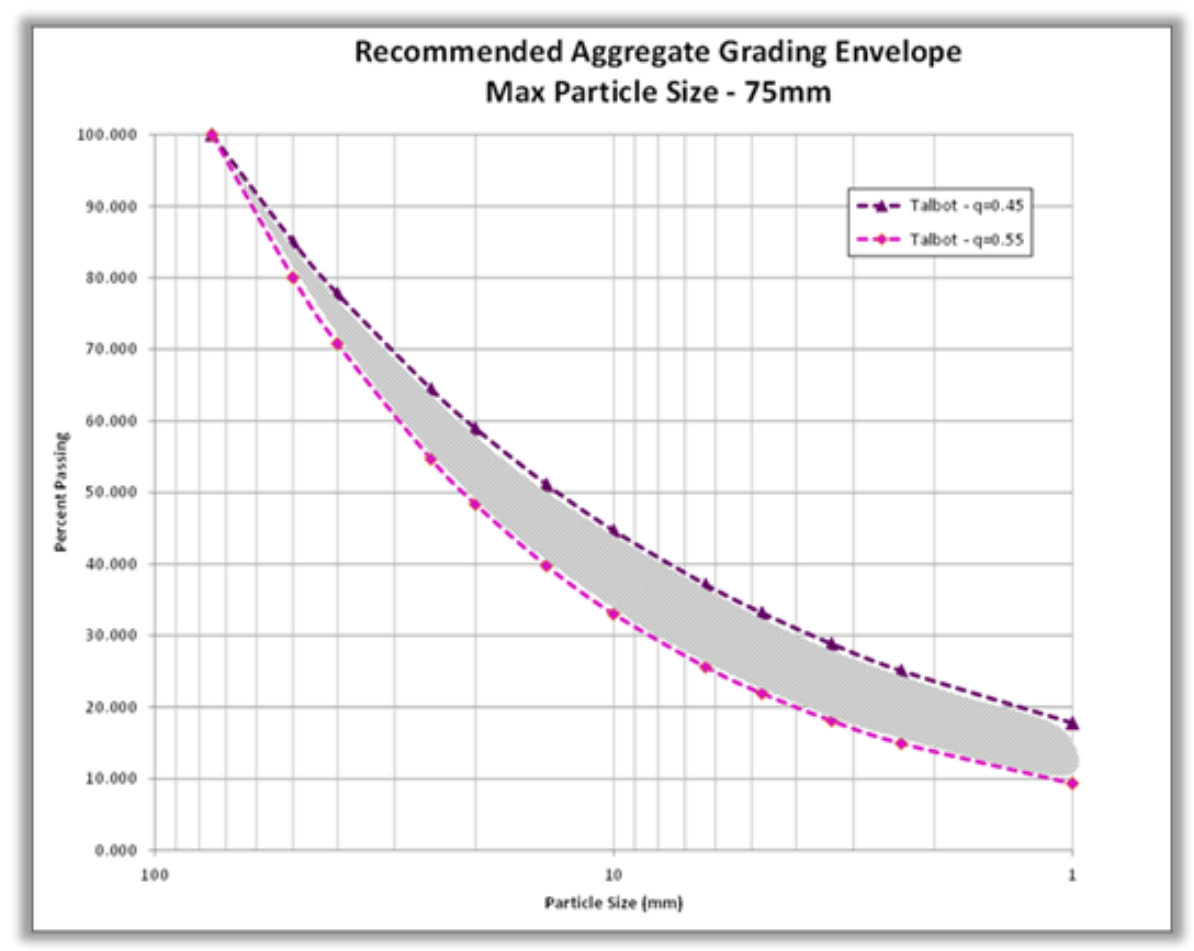

Figure 1 Talbot curve

For backfill, the Talbot curve can be extrapolated to larger particles to achieve the required strengths with a minimum of cement addition. The addition of large particles in the development waste rock essentially removes an equivalent amount of cemented fines matrix. As long as the ratio of cemented fines to coarser rock is not too low, all the spaces between the coarse particles will be filled with cemented material and all the coarse particles fill a space without any cement required to achieve a much higher strength than the cemented fines material. From this description it may appear that the strength of the overall fill mass will be the strength of the cemented matrix and if the target strength is met with a cemented paste-fill content of $5 \%$ cement content then a mixture 50/50 mixture of paste-fill and rock would require only $2.5 \%$ cement content to achieve the same target strength as the $5 \%$ cement content paste-fill.

However, there is an additional mechanical strength gain associated with the coarse particle to coarse particle interlocking that begins to increase strengths beyond the strength of the fine cemented matrix. This strength increase is dependent on the strength of the rock since the point to point contact between coarse rock particles impart a large load over a small area.

\subsection{Eliminate material handling costs to transport rock to surface}

The cost to transport rock to surface is highly dependent on the mines material handling system, location of waste rock dump and properties of the waste rock.

Deep mines with multiple shafts have the most to gain from a reduction in waste haulage. Shallower ramp haulage mines also have much to gain as they extend deeper since the haulage cost goes up substantially with depth.

Mines that have geochemically problematic waste rock with Acid Rock Drainage (ARD) or other environmental concerns will have additional costs associated with waste dump construction, operation and closure.

Long travel distances from the mine access to the waste dump also increase the material handling costs.

Although the handling of waste rock can't be completely eliminated when disposing of waste in the stopes the amount of waste rock handling cost is considerably less than haulage to surface. 


\subsection{Minimize effort to incorporate the waste rock into the fill}

Many of the previous attempts to incorporate waste rock into fill have relied upon a crushed waste rock product, long delivery conveyors, raises and other infrastructure. It is most desirable to use the waste rock as is, without any further particle size sorting or modification. In addition, it is desirable to be able to move the waste rock into the stope with minimal effort.

The least amount of effort to incorporate waste rock occurs when the development is near to the deposition point and ideally on the same working level. Some equipment will be required to incorporate the waste rock into the fill and will be discussed in later sections.

\subsection{Allow the co-disposal of waste rock at all times}

Although this goal is impossible to achieve at all times it is possible to partly reach this goal. The initial development of the mine will require waste rock to be removed but as soon as the first stope is ready for backfill there is the opportunity to dispose of waste rock.

Co-disposal of waste rock would need to be another part of the mine scheduling if it were to be optimized. This is potentially a major impediment to the concept of using waste rock underground because it is another 'optional' task which may be passed over in order to achieve core objectives such as tonnes of ore mined etc.

The added complexity of scheduling development and waste rock filling to occur at certain times will require more attention however if the potential cost savings are adequately high it is worth the extra effort. As with all new initiatives that mine operators are not familiar with there will need to be leadership and commitment to making the co-disposal of waste rock a normal part of the mining cycle.

\section{$4 \quad$ Waste rock co-disposal solution}

Given the potential benefits of waste rock co-disposal and the ideal design criteria described above, Golder has worked with Conveyor Application Systems (CAS) to develop a potential solution that satisfies the ideal criteria.

The concept is based on CAS's self-propelled slinger vehicle which has been used in many mining applications for the distribution of stemming material, aggregate and concrete. The slinger receives material into a hopper and then meters that material out of the hopper and into a high speed slinger conveyor which throws the material in a direction that is controlled by the slinger. The tilt angle of the slinger and the slinger speed can be modified so that the distance of throw and trajectory are also modifiable.

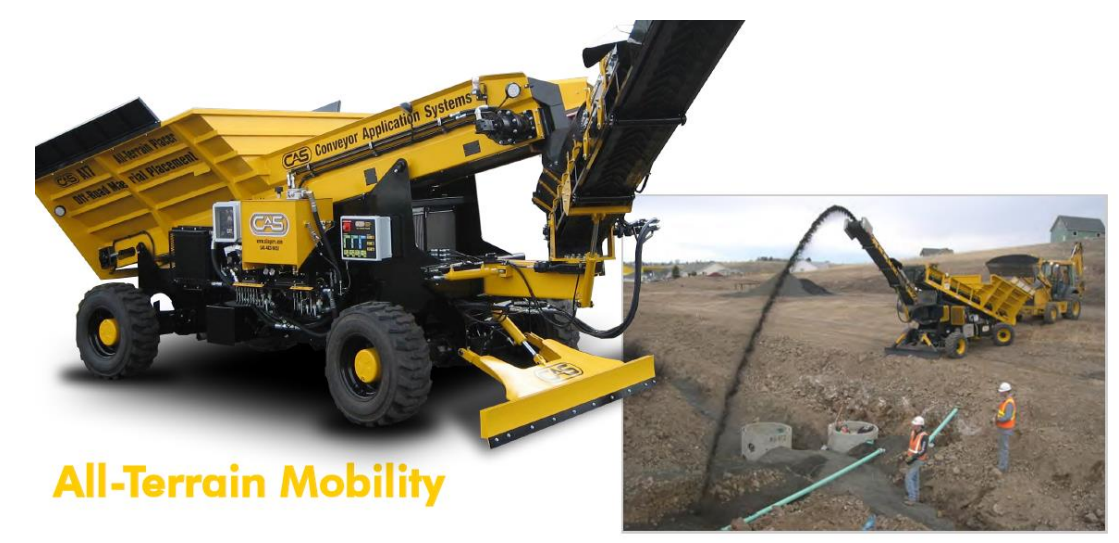

Figure 2 CAS slinger 


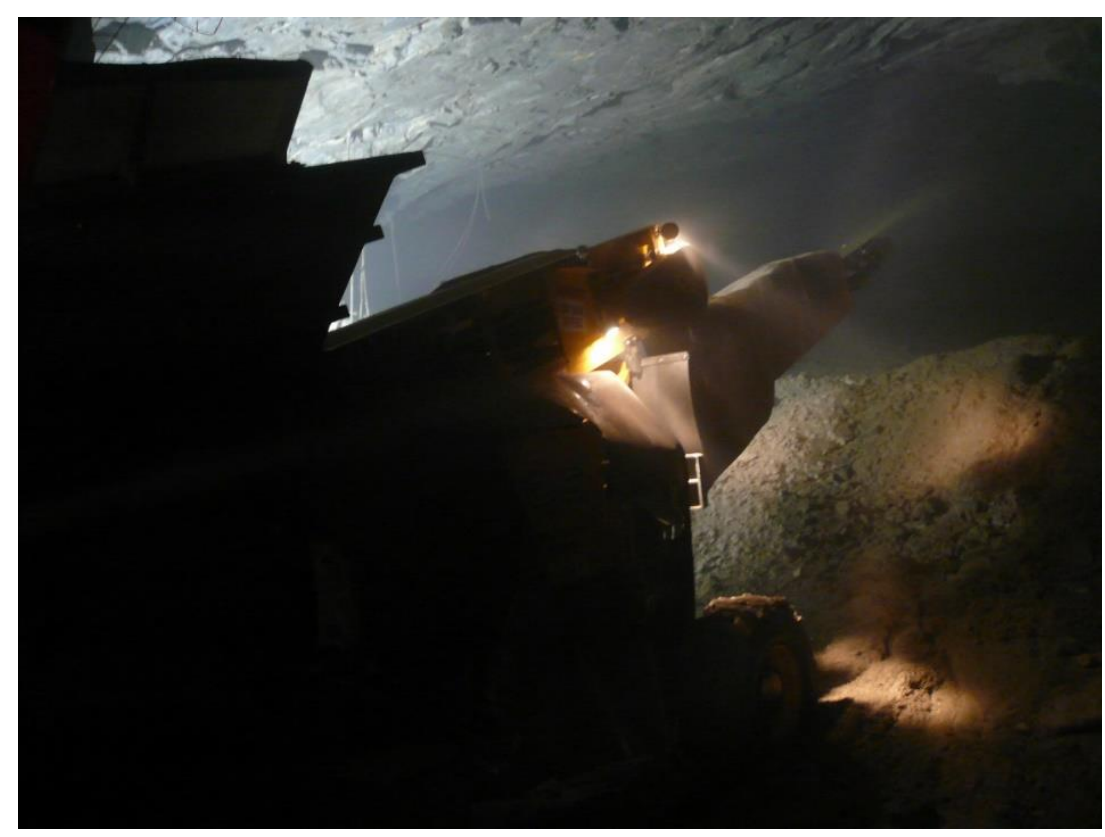

\section{Figure 3 Filling voids underground}

Although this equipment fits most of the needs of an underground co-disposal system there are some areas where the equipment can be improved in order to function better for the specific needs of the mine environment. The areas that needed to be addressed were identified as:

- $\quad$ Must be able to accommodate large rocks up to $300 \mathrm{~mm}$ in size.

- Must have grizzly to reject rocks that are larger than $300 \mathrm{~mm}$.

- Must have the ability to blend the rock and paste prior to discharging both into the stope.

- Must be robust and suitable for the underground mine environment.

- Must be towable by scoop or service vehicle.

Based on the above list of required features CAS has performed some preliminary design on a prototype machine that would fit the requirements of underground waste rock co-disposal.

Screenshots of the design are shown in Figures 4 and 5 below:

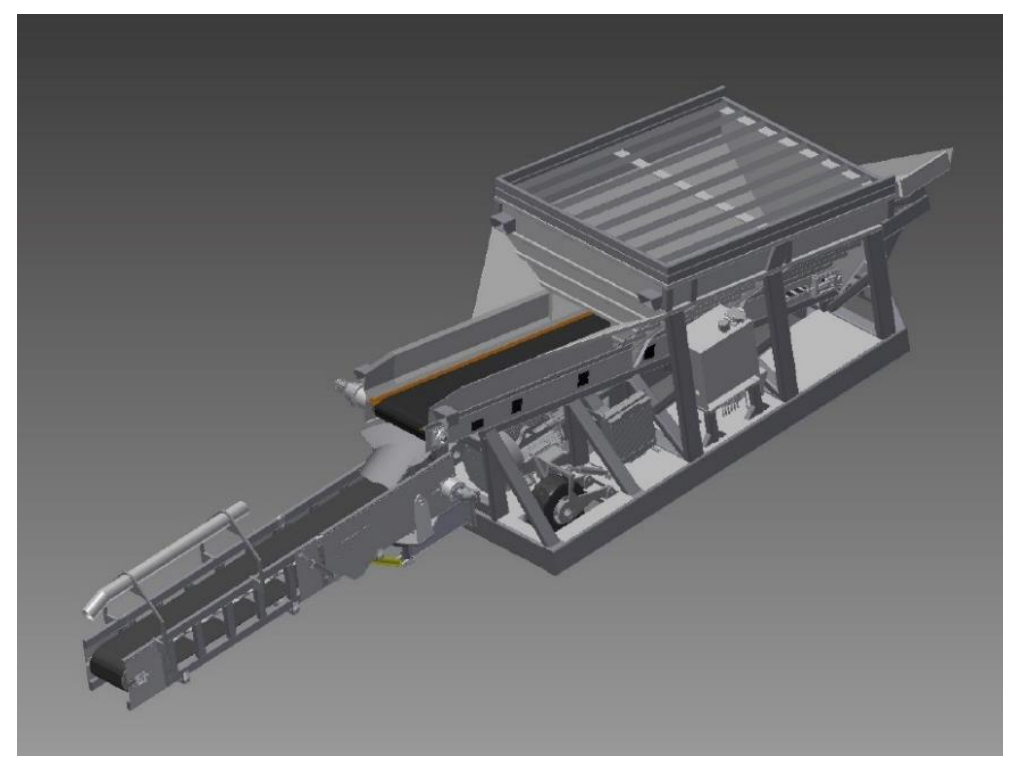

Figure 4 Prototype codisposal machine 


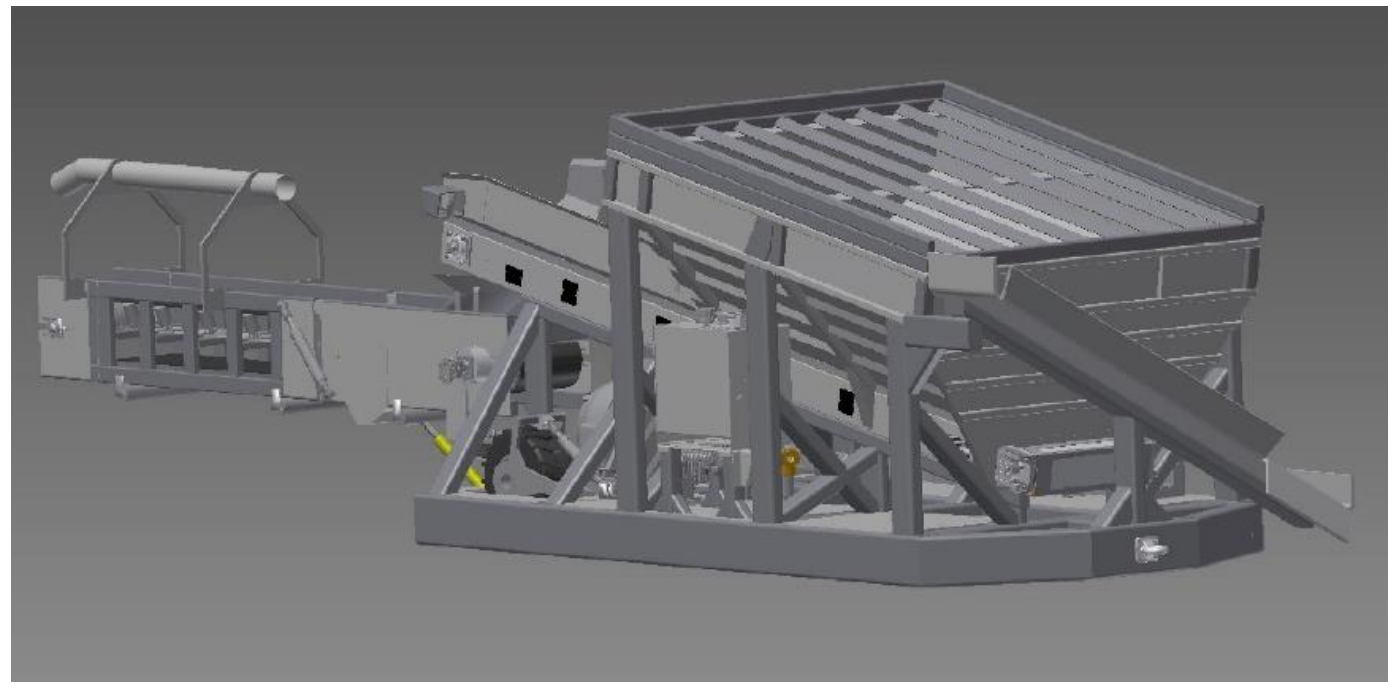

Figure 5 Prototype codisposal machine

\section{$5 \quad$ Methods of operation}

The co-disposal machine would be towed to the top sill of an empty stope requiring fill. The machine has a set of trailer tires and jacking mechanism that allows the tires to project below the skid. When towed to the stope the tires would be retracted and the entire skid assembly would rest on the sill floor.

The skid has an integral paste discharge line which would be connected to a paste-fill pipeline header using a flexible material handling hose.

Waste rock would only be discharged into the stope during a paste pour. The paste pour would commence and shortly after paste had entered the stope, the waste rock co-disposal machine could be activated. When activated a scoop would dump waste rock into the hopper which would meter the rock out onto the slinger conveyor. The slinger would accelerate the waste rock and fling it off of the end of the conveyor. Paste discharges at the slinger head end and would mix with the rock stream as it is projected out into the stope.

The slinger direction, tilt angle and speed will be controlled by the onboard PLC so that rock is spread around the stope in a consistent pattern so that no areas receive surges of waste rock. This wide spread of the waste rock will allow a much greater quantity of rock to be discharged into the stope compared to dumping scoop buckets over the brow of the stope.

Any oversize from the grizzly will be rehandled by a scoop to a secondary stope where the presence of large rocks is not a problem.

\section{Summary}

The co-disposal of waste rock with backfill has a significant cost advantage in many mines that have expensive waste rock haulage or expensive backfill. Depending on the cost of those two items and other, secondary costs, a waste rock co-disposal machine may be of benefit to the mine operation.

The machine design presented in this paper could potentially fill the need for a co-disposal method that can achieve the desired benefits of co-disposal without the disadvantages typically seen in previous methods of co-disposal.

Currently several mines are considering the trial of this co-disposal method and it is hoped that within a year a test case will be available in order to evaluate the potential for this technology. 


\section{References}

Kuganathan K., Sheppard I. 2001, 'A non-segregating 'Rocky Paste Fill' (RPF) produced by co-disposal of cemented de-slimed tailings slurry and graded rockfill', Minefill 2001: 7th International Symposium on Mining with Backfill 2001, pp. 27-41. 